\title{
Variabilidade genética de amostras de Salmonella Typhi isoladas de surto e de casos esporádicos ocorridos em Belém, Brasil
}

\author{
Genetic variability of Salmonella Typhi samples isolated from outbreaks and sporadic cases of typhoid fever in \\ Belém, Brazil
}

Flávia Corrêa Bastos'; Karla Valéria Batista Lima²; Lena Lílian Canto de Sá3; Cintya de Oliveira Souza4; Maria Luíza Lopes ; Francisco Lúzio de Paula Ramos ${ }^{6}$

unitermos
Salmonella Typhi
Febre tifóide
PFGE
Surto
Casos esporádicos

\section{resumo}

Introdução: Salmonella Typhi é o agente da febre tifóide (doença caracterizada por febre, cefaléia, mialgia, artralgia, diarréia ou constipação), cujo quadro pode se complicar e levar o paciente a óbito. No Brasil, a febre tifóide é endêmica nas regiões Norte e Nordeste, com surtos ocorridos nos meses de intenso calor. Objetivo: Analisar e comparar a variabilidade genética de S. Typhi isoladas de surto e casos esporádicos de febre tifóide ocorridos em determinado período na cidade de Belém (PA). Material e métodos: Foram analisadas 20 amostras de S. Typhi: 10 isoladas de um surto ocorrido no bairro do Guamá, Belém, entre os meses de dezembro/2005 e março/2006, e 10 de casos esporádicos ocorridos em diferentes localidades da mesma cidade e no mesmo período do surto. A caracterização genética foi realizada pela análise do perfil de macrorrestrição obtido pela enzima Xbal e definido por eletroforese em gel de campo pulsado (PFGE). Resultados: A análise de Xbal-PFGE das amostras estudadas demonstrou uma similaridade genética de $83 \%$ a 100\%. Conclusão: Este estudo pôde demonstrar a relação clonal das amostras $S$. Typhi causadoras de surto e de casos esporádicos de febre tifóide ocorridos na cidade de Belém no período de dezembro/2005 a março/2006.

\section{abstract}

Background: Salmonella Typhi is the causative agent of typhoid fever, illness characterized by fever, migraine, myalgia, arthralgia, diarrhea or constipation, which may have complications and cause death. In Brazil, the typhoid fever is endemic in the Northern and Northeastern regions, with outbreaks occurring in scorching months. Objective: To analyse and compare the genetic variability of S. Typhi strains isolated from outbreaks and sporadic cases of typhoid fever occurred in the city of Belém (PA) between December 2005 and March 2006. Material and methods: Twenty samples of S. Typhi were analyzed: 10 of them were isolated from an outbreak occurred in Guamá neighborhood in Belém, between December 2005 and March 2006, and the other 10 were isolated from sporadic cases in different neighborhoods of the same city in the same outbreak period. The genetic characterization was performed by macrorestriction analysis of genomic DNA with Xbal enzyme defined by pulsed-field gel electrophoresis (PFGE). Results: The Xbal-PFGE analysis of the studied samples revealed a genetic similarity of $83 \%$ to $100 \%$. Conclusion: This study demonstrated the clonal relation between the S. Typhi samples from the outbreak and from the sporadic cases of typhoid fever occurred in the city of Belém between December 2005 and March 2006. key words

Salmonella Typhi

Typhoid fever

PFGE

Outbreak

Sporadic cases

1. Estudante de doutoramento no Instituto de Ciências Biológicas da Universidade Federal do Pará (UFPA).

2. Pesquisadora responsável pelo Laboratório de Biologia Molecular da Seção de Bacteriologia do Instituto Evandro Chagas (IEC).

3. Pesquisadora responsável pelo Laboratório de Microbiologia da seção de Meio Ambiente do IEC.

4. Farmacêutica; mestre; Seção de Bacteriologia do IEC.

5. Chefe da Seção de Bacteriologia do IEC.

6. Médico pesquisador da Seção de Bacteriologia do IEC.

Trabalho realizado no Laboratório de Enterobactérias, na Seção de Bacteriologia do IEC. 


\section{Introdução}

Salmonella enterica sorovar Typhi é o agente etiológico da febre tifóide. É responsável por 22 milhões de novos casos por ano no mundo, $5 \%$ dos quais são fatais ${ }^{(4,7)}$. Hoje a maioria dos surtos dessa doença ocorre em países em desenvolvimento ${ }^{(15)}$.

A transmissão da enfermidade se dá pela ingestão de água ou de alimentos contaminados com fezes humanas ou, menos freqüentemente, com urina contendo a bactéria; mais raramente pode ser transmitida pelo contato direto (mão/boca) com fezes, urina, secreção respiratória, vômito ou pus proveniente de indivíduo infectado. A doença se caracteriza clinicamente por febre, cefaléia, diarréia e/ou constipação, dor abdominal, podendo causar ainda danos respiratórios, hepáticos, esplênicos e neurológicos. A emergência da resistência bacteriana aos antibióticos disponíveis pode ainda ser um fator agravante dessa salmonelose, já que o tratamento de indivíduos com febre tifóide consiste basicamente em antibióticos e reidratação.

O ácido gástrico constitui a primeira barreira natural contra Salmonella. Aquela que consegue transpor essa barreira chega ao intestino delgado e, após invadir a parede do órgão, alcança a circulação sanguínea. Daí a bactéria pode atingir qualquer órgão. Porém atinge preferencialmente órgãos do sistema fagocítico monocitário, como fígado, baço, medula óssea e vesícula biliar.

A forma mais efetiva de impedir a instalação e a disseminação da doença em uma localidade é implantando saneamento básico e fornecendo água potável para toda a população, além de campanhas educativas salientando a importância da higiene domiciliar e pessoal. Cabe ainda ressaltar que o diagnóstico precoce e o tratamento adequado ajudam a diminuir o aparecimento de novos casos.

A fagotipagem, até pouco tempo atrás, era o método mais comumente utilizado para a caracterização de S. Typhi, porém essa técnica apresenta limitações, em virtude de se basear somente no fenótipo. Daí a tendência atual de se primar por técnicas moleculares, por serem mais discriminatórias e, portanto, mais apropriadas para aplicação em estudos epidemiológicos ${ }^{(12)}$.

Diversos métodos na esfera molecular têm sido aplicados na tipagem dessa espécie bacteriana: análise de polimorfismos para sítios de restrição, ribotipagem, análise de seqüências nucleotídicas e eletroforese de campo pulsado (PFGE). A última tem sido utilizada com sucesso no estudo do ácido desoxirribonucleico (DNA) cromossomal de diver- sos patógenos em investigações epidemiológicas. O perfil eletroforético gerado por PFGE permite clara diferenciação polimórfica das amostras com poucas dificuldades de interpretação e ambigüidades quando comparado com outras técnicas moleculares ${ }^{(19)}$. Por isso é considerado padrão-ouro para genotipagem entre as salmonelas.

O objetivo deste trabalho foi avaliar a variabilidade genética de amostras de $S$. Typhi isoladas de surto e de casos esporádicos de febre tifóide, ocorridos na cidade de Belém (Pará) e comparar os perfis eletroforéticos gerados por PFGE entre elas.

\section{Material e métodos}

\section{Amostras bacterianas}

Vinte amostras de S. Typhi isoladas no período de dezembro de 2005 a março de 2006 na Seção de Bacteriologia do Instituto Evandro Chagas (IEC) foram analisadas. Dez delas foram isoladas de um surto ocorrido no bairro do Guamá, na periferia da cidade de Belém (Tabela 1); as demais foram isoladas de casos não relacionados com o surto, ocorridos em diferentes localidades da mesma cidade, detectados em pacientes que procuraram atendimento médico no ambulatório da Seção de Bacteriologia do IEC (Tabela 2). Todas as amostras foram isoladas a partir de sangue e/ou fezes, pelos métodos de hemocultura ou coprocultura, respectivamente. As amostras foram identificadas por testes bioquímicos-padrão e confirmados por teste de aglutinação em lâmina, utilizando-se anti-soros, somáticos, flagelar e de envoltório específicos para Salmonella Typhi.

\section{Eletroforese em gel de campo pulsado}

Foi realizada para avaliar a relação clonal entre as amostras de S. Typhi estudadas, utilizando-se a técnica de acordo com Gautom (1997) ${ }^{(6)}$, mas com algumas modificações. A digestão do DNA extraído em miniblocos de agarose foi feita pela enzima de restrição Xbal a $37^{\circ} \mathrm{C}$ por 16 a 18 horas. A corrida eletroforética foi realizada em sistema de eletroforese do tipo CHEF-DR III (Bio-Rad). A eletroforese ocorreu por um período de 24 horas a $160 \mathrm{~V}$, com pulso inicial de $5 \mathrm{~s}$ e final de $50 \mathrm{~s}$ em tampão de corrida TBE (trisborato + ácido etilenodiaminotetracético [EDTA]) 0,5x.

Os perfis eletroforéticos gerados por PFGE foram analisados utilizando-se o software BioNumerics (Applied Maths, Belgium), e a similaridade entre esses perfis foi avaliada com base no coeficiente de similaridade Dice (3\% de tolerância). 


\section{Tabela 1 Amostras analisadas de S. Typhi isoladas durante surto de febre tifóide}

\begin{tabular}{|c|c|c|c|c|}
\hline Registro & Data de isolamento & Exame & Idade & Sexo \\
\hline 2628 & 05/12/06 & Coprocultura e hemocultura & 19 & M \\
\hline 082 & 9/1/06 & Coprocultura e hemocultura & 34 & M \\
\hline 400 & $9 / 2 / 06$ & Coprocultura & 37 & $\mathrm{~F}$ \\
\hline 401 & $9 / 2 / 06$ & Coprocultura & 34 & M \\
\hline 460 & $13 / 2 / 06$ & Coprocultura & 25 & $\mathrm{~F}$ \\
\hline 695 & $3 / 3 / 06$ & Hemocultura & 53 & $\mathrm{~F}$ \\
\hline 889 & $15 / 3 / 06$ & Coprocultura e hemocultura & 31 & M \\
\hline 717 & $27 / 3 / 06$ & Hemocultura & - & $\mathrm{F}$ \\
\hline 723 & $27 / 3 / 06$ & Hemocultura & - & $\mathrm{F}$ \\
\hline 1006 & 29/3/06 & Coprocultura e hemocultura & 41 & $\mathrm{~F}$ \\
\hline
\end{tabular}

\section{Tabela 2 Amostras analisadas de S. Typhi isoladas de casos esporádicos de febre tifóide}

\begin{tabular}{lllcc}
\hline Registro & Data de Isolamento & Exame & Idade & Sexo \\
\hline 2721 & $15 / 12 / 05$ & Coprocultura & 6 & $\mathrm{~F}$ \\
0019 & $3 / 1 / 06$ & Coprocultura & 66 & $\mathrm{M}$ \\
157 & $3 / 1 / 06$ & Coprocultura & 26 & $\mathrm{M}$ \\
226 & Hemocultura & 23 & $\mathrm{~F}$ \\
299 & $23 / 1 / 06$ & Coprocultura & 12 & $\mathrm{M}$ \\
350 & $1 / 2 / 06$ & Coprocultura & 18 & $\mathrm{M}$ \\
685 & $22 / 2 / 06$ & Coprocultura & 21 & $\mathrm{M}$ \\
798 & $2 / 3 / 06$ & Hemocultura & 23 & $\mathrm{M}$ \\
694 & $3 / 3 / 06$ & Coprocultura & 48 & $\mathrm{M}$ \\
1270 & $29 / 3 / 06$ & Hemocultura & 35 & $\mathrm{M}$
\end{tabular}

As amostras foram consideradas geneticamente idênticas quando houve completa concordância (100\%) entre os perfis $^{(16)}$.

\section{Resultados}

\section{Eletroforese em gel de campo pulsado}

A análise do polimorfismo de macrorrestrição obtido pela enzima Xbal revelou baixa diversidade nos perfis gerados por PFGE para todas as amostras de S. Typhi analisadas, compartilhando similaridade em torno de $83 \%$ a $100 \%$ (Figura 1). Entre as amostras provenientes do surto, observou-se a formação de dois grupamentos distintos principais: S1 $(695,717,723,1006,889)$ e S2 $(082,400)$ (Figura 2), apresentando $100 \%$ de similaridade entre as amostras de cada grupo. Dois grupamentos distintos e principais também foram observados entre as amostras dos casos esporádicos de febre tifóide: N1 (157, 266, 299) e N2 $(685,694,798)$ (Figura 3). Essa análise pôde ainda revelar similaridade de $100 \%$ entre os grupos S1 e N1 (Figura 1). 


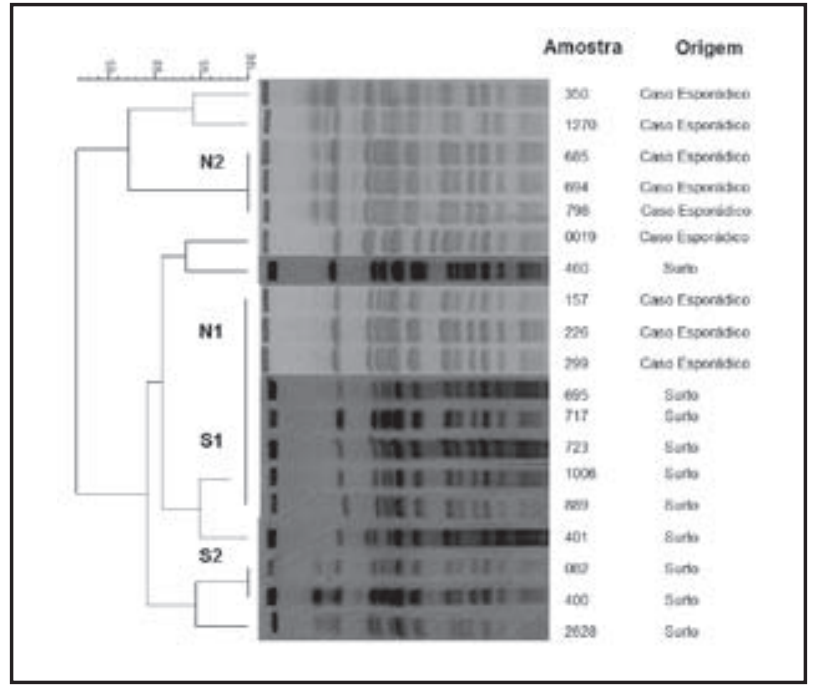

Figura 1 - Dendograma da relação clonal das amostras S. Typhi isoladas de surto e casos esporádicos de febre tifóide determinada pela análise de macrorrestrição do DNA genômico com Xbal

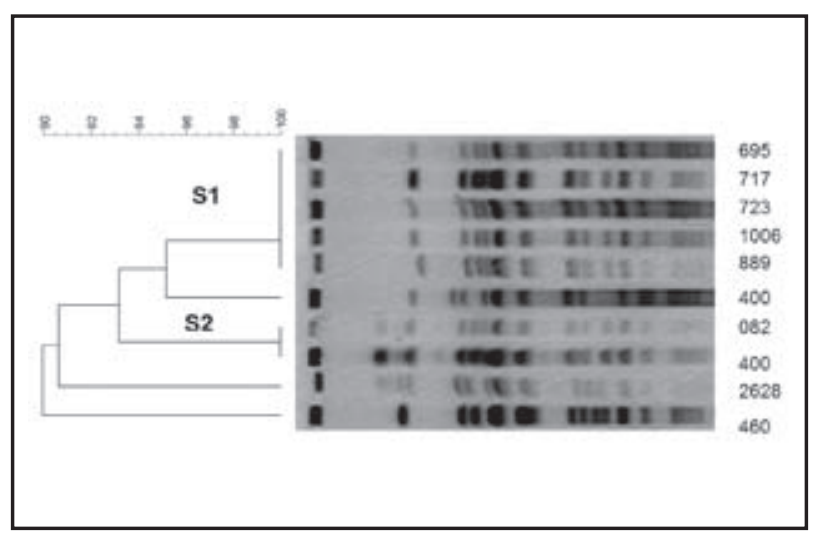

Figura 2 - Dendograma da relação clonal das amostras S. Typhi isoladas de surto de febre tifóide determinada pela análise de macrorrestrição do DNA genômico com Xbal

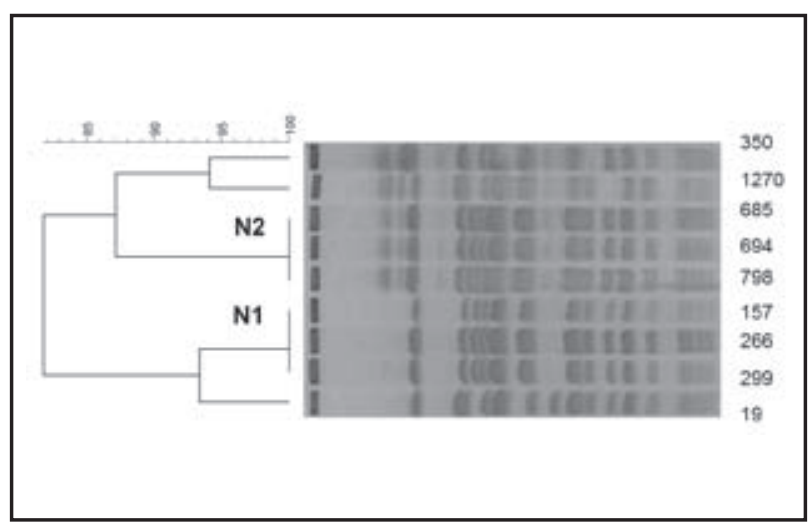

Figura 3 - Dendograma da relação clonal das amostras S. Typhi isoladas de casos esporádicos de febre tifóide determinada pela análise de macrorrestrição do DNA genômico com Xbal

\section{Discussão}

No estado do Pará alguns surtos foram registrados nos últimos anos: Óbidos (1997), Mojú (1999) e Anajás (2001), todos detectados e acompanhados por técnicos do IEC, de Belém.

A ocorrência de Salmonella Typhi está associada a precárias condições de saneamento básico, higiene pessoal e ambiental, estando sua distribuição estreitamente relacionada com o desenvolvimento socioeconômico de cada área, refletindo as desigualdades sociais. Uma nítida e peculiar distribuição sazonal é verificada no estado do Pará, já que mais de 70\% dos casos da doença são registrados durante o período de intenso calor, entre os meses de julho e dezembro ${ }^{(13,14)}$.

Os perfis de macrorrestrição obtidos pela análise das amostras S. Typhi evidenciam relação de similaridade genética significativa entre elas. O polimorfismo das amostras relacionadas com o surto evidencia a presença de cinco genótipos idênticos de S. enterica Typhi, dois deles com maior distribuição (S1 e S2) (Figura 2).

A genotipagem de amostras aparentemente não-relacionadas evidenciou a ocorrência de dois surtos: um deles ocorrido em janeiro de $2006(157,226,299)$ e outro no final de fevereiro de 2006 (685, 694 e 798). No primeiro surto (perfil N1) (Figura 1) a amostra foi capaz de permanecer na população local, reaparecendo em março de 2006 com novo surto (S1) (Figura 1). Isso está provavelmente relacionado com o fato de o homem participar, como portador, da cadeia de transmissão dessa salmonelose, sendo possível identificá-lo mediante o isolamento de $S$. Typhi com perfil idêntico ao das amostras endêmicas. Os clones endêmicos podem ainda permanecer na comunidade contaminando água e alimentos.

Ao se avaliarem as amostras provenientes do surto ocorrido no bairro do Guamá (Figura 2), observaram-se $90 \%$ de similaridade compartilhada. A pequena diversidade observada entre as amostras agrupadas e não-agrupadas pode ser decorrente da presença de um ancestral comum que persiste na comunidade através de portadores. A diversidade pode, então, ser justificada pelo acúmulo de alterações genéticas ocorridas.

Uma grande diversidade genética de amostras $S$. enterica Typhi, isoladas de casos esporádicos e surtos de febre tifóide ou de ambientes, tem sido descrita quando tais amostras são submetidas à tipagem por $\operatorname{PFGE}^{(1,3,10,17,18)}$. A eletroforese de campo pulsado pode ser desenvolvida após 
tratamento do DNA genômico com diferentes enzimas de restrição como Xbal, Spel e Avrll. No entanto, maior poder discriminatório tem sido relatado após utilização de Xbal, enzima selecionada para o desenvolvimento dos ensaios apresentados neste artigo ${ }^{(9,5,11,21)}$.

A determinação de genótipos em surtos ou casos esporádicos é importante do ponto de vista epidemiológico, pois permite investigar a fonte de infecção, estabelecer a relação entre os casos clínicos e, com esse resultado, propor medidas que evitem a dispersão dos patógenos, além de controlar novos surtos.

Vale ressaltar que ao se analisarem os perfis gerados por PFGE de todas as amostras (Figura 1), uma similaridade em torno de $83 \%$ e de $100 \%$ (S1 e N1) foi verificada.

Vários estudos utilizaram a técnica de PFGE para avaliar epidemiologicamente amostras de S. Typhi, tanto de surtos como de casos esporádicos, confirmando a co-existência de múltiplos clones endêmicos $(3,10,18)$.

Thong et al. ${ }^{(17)}$ analisaram isolados de S. Typhi provenientes de surto e casos esporádicos ocorridos na Malásia entre os anos de 1987 e 1991. Chandel e Chaudhry ${ }^{(2)}$ encontraram um único clone entre amostras de S. Typhi isoladas na Índia durante cinco anos. Outros autores, como Kariuki et al. ${ }^{(8)}$, também relataram a presença de um surto de febre tifóide no Quênia; já Thong et al. ${ }^{(20)}$ observaram aumento da diversidade genética de isolados de S. Typhi na Nova Guiné de 1992 a 1999.

Deve-se ressaltar a importância dos resultados obtidos pela análise dos perfis gerados por PFGE, através dos quais foi possível sugerir a presença de um genótipo associado às amostras isoladas do surto e de casos esporádicos de febre tifóide na cidade de Belém, revelando que diferentes pessoas em diferentes localidades da cidade podem estar sendo contaminadas pelos mesmos genótipos de S. Typhi.

\section{Conclusão}

Em conclusão, os perfis gerados por PFGE pelas amostras isoladas dos casos esporádicos de febre tifóide bem como aquelas constituintes do surto demonstraram uma pequena diversidade genética, sugerindo o estabelecimento de um único genótipo de $S$. Typhi na cidade de Belém no período de dezembro de 2005 a março de 2006.

\section{Referências}

1. CARREIRA, A. G. A. Caracterização molecular de Salmonella Typhi isoladas de surtos e casos esporádicos de febre tifóide ocorridos no estado do Pará. Belém, 2004. Dissertação (mestrado) - Centro de Ciências Biológicas, Universidade Federal do Pará.

2. CHANDEL, D. S.; CHAUDHRY, R. Molecular typing reveals a unique clone of Salmonella enterica serotype Typhi among Indian strains. J Clin Microbiol, v. 44, p. 2673 5, 2006.

3. CONNERTON, P. et al. Epidemic typhoid in Vietnam: molecular typing of multiple-antibiotic-resistant Salmonella enterica serotype Typhi from four outbreaks. J Clin Microbiol, v. 38, p. 895-7, 2000.

4. CRUMP, J. A.; LUBY, S. A. P.; MINTZ, E. D. The global burden of typhoid fever. Bull WHO, v. 82, p. 346-53, 2004.

5. EJRNAES, K. et al. Pulsed-field gel electrophoresis typing of Escherichia coli strains from samples collected before and after pivmecillinam or placebo treatment of uncomplicated community-acquired urinary tract infection in women. J Clin Microbiol, v. 44, p. 1776-81, 2006.

6. GAUTOM, R. K. Rapid pulsed-field gel electrophoresis protocol for typing of Escherichia coli 0157:H7 and other Gram-negative organisms in 1 day. J Clin Microbiol, v. 35, p. 2977-980, 1997.

7. IVANOFF, B. C. C. C. The diagnosis, prevention, and treatment of typhoid fever. Geneva: WHO, 2003.

8. KARIUKI, S. et al. Characterization of multidrug-resistant typhoid outbreaks in Kenya. J Clin Microbiol, v. 42, p. 1477-82, 2004.

9. KUBOTA, K. et al. Analysis of Salmonella enterica serotype Typhi pulsed-field gel electrophoresis patterns associated with international travel. J Clin Microbiol, v. 43, p. 1205-9, 2005.

10. LING, J. M. etal. Molecular methods for the epidemiological typing of Salmonella enterica serotype Typhi from Hong Kong and Vietnam. J Clin Microbiol, v. 38, p. 292-300, 2000. 
11. MAMMINA, C.; ALEO, A.; ROMANI, C.; NASTASI, A. Shigella sonnei biotype g carrying class 2 integrons in southern Italy: a retrospective typing study by pulsed field gel electrophoresis. BMC Infect Dis, v. 6, p. 117, 2006.

12. NAVARRO, F. et al. Molecular typing of Salmonella enterica sorovar Typhi. J Clin Microbiol, v. 34, p. 2831-4, 1996.

13. QUINTAES, B. R. et al. Conventional and molecular typing of Typhi strains from Brazil. Rev Inst Med Trop S Paul, v. 44, p. 315-9, 2002.

14. RAMOS, F. L. P. Relatório de investigação epidemiológica de surto de febre tifóide no município de Mojú, Pará. Belém: Instituto Evandro Chagas/FUNASA/MS, 2001.

15. SINHÁ, A. et al. Typhoid fever in children aged less than 5 years. Lancet, v. 354, p. 734-7, 1999.

16. TENOVER, F. C. et al. Interpreting chromosomal DNA restriction patterns produced by pulsed-field gel electrophoresis: criteria for bacterial strain typing. J Clin Microbiol, v. 33, p. 2233-9, 1995.
17. THONG, K. L. et al. Epidemiologic analysis of sporadic Salmonella Typhi isolates and those from outbreaks by pulsed-field gel electrophoresis. J Clin Microbiol, v. 32, p. 1135-41, 1994.

18. THONG, K. L. et al. Analysis of Salmonella typhi isolates from Southeast Asia by pulsed-field gel electrophoresis. J Clin Microbiol, v. 33, p. 1938-41, 1995.

19. THONG, K. L. et al. Molecular analysis of environmental and human isolates of Salmonella typhi. App/ Environ Microbiol, v. 62, p. 271-4, 1996.

20. THONG, K. L. et al. Increasing genetic diversity of Salmonella enterica serovar Typhi isolates from Papua New Guinea over the period from 1992 to 1999. J Clin Microbiol, v. 40, p. 4156-60, 2002.

21. VAZ, T. M. I. et al. Genetic heterogeneity of Shiga toxinproducing Escherichia coli strains isolated in São Paulo, Brazil, from 1976 through 2003, as revealed by pulsed-field gel electrophoresis. J Clin Microbiol, v. 44, p. 798-804, 2006. 